RNA-Biologie

\title{
RNA-Live-Imaging in Mikroorganismen
}

KIRA MÜNTJES, MICHAEL FELDBRÜGGE

INSTITUT FÜR MIKROBIOLOGIE, CLUSTER OF EXCELLENCE ON PLANT SCIENCES, UNIVERSITÄT DÜSSELDORF

\section{RNA live imaging is a powerful technique to visualize the subcellular localization as well as highly dynamic transport of mRNAs in vivo. Established in eukaryotic microorganisms, it is now a wide-spread system used in bacteria, animals, and plants. The method is based on the binding of heterologous RNA-binding proteins to their cognate binding sites that are integrated into the mRNA of interest. Recent advances enable the visualization of transcriptional or translational sites as well as mRNA decay.}

DOI: $10.1007 / \mathrm{s} 12268-020-1323-4$

(C) Die Autoren 2020

mRNAs codieren Proteine und bilden damit die Grundlage des zellulären Lebens. Zusammen mit interagierenden RNA-bindenden Proteinen (RBPs) formen sie große mRNA-Ribonukleoprotein(mRNP)-Komplexe. Angefangen bei der Transkription im Nukleus, über den Export, den Transport und die Translation im Cytoplasma, kontrolliert die Zelle durch die Interaktion mit RBPs die Expression der mRNA auf zeitlicher und räumlicher Ebene. Diese gewährleistet die korrekte subzelluläre Lokalisation und die Expression der codierten Proteine. Eine wichtige Methode, mRNAs in vivo zu untersuchen, ist das RNA-Live-Imaging. Mit dieser Technik kann sowohl die räumliche als auch die zeitliche Lokalisation von mRNAs von der Transkription bis hin zum Abbau in lebenden Zellen mikroskopisch untersucht werden.

\section{Methodik des RNA-Live-Imagings}

Das grundlegende Prinzip dieser Technik ist der Nachweis heterologer RBPs, die ihre Bindemotive spezifisch und hochaffin in ZielmRNAs erkennen. Die drei häufigsten verwendeten RBPs sind Phagenproteine: ein 22 Aminosäuren langes, N-terminales Fragment des Antiterminators $\lambda \mathrm{N}$ oder Hüllpro- teine aus den MS2- und PP7-Phagen (MS2-CP und PP7-CP, CP: coat protein; Abb. 1, [1]). Im Falle des monomeren $\lambda \mathrm{N}$ wird eine mutierte, stärker bindende Variante $\lambda \mathrm{N}^{*}$ verwendet. Die als Dimer bindenden MS2-CP und PP7CP wurden so modifiziert, dass sie keine oligomeren Strukturen mehr ausbilden. Um zwischen gebundenen und ungebundenen RBPs zu unterscheiden, werden in eukaryotischen Systemen Kernlokalisierungssignale (NLS) verwendet. Auf diese Weise gelangen ungebundene RBPs in den Kern, was die Hintergrundfluoreszenz im Cytoplasma verringert.

Die Integration der zugehörigen RNA-Bindemotive erfolgt vorzugsweise in die 3'-untranslatierte Region (3'-UTR) der mRNA. Zur Verbesserung des Nachweises werden mehrere Kopien des Bindemotivs verwendet, meist zwischen 16 und 24 Kopien. Die Insertion des Bindemotivs und die Expression des Phagenproteins dürfen dabei die Funktion der mRNA nicht einschränken. In transgenen Mäusen konnte z. B. durch die Integration von 24 Kopien der MS2-Bindestellen die ubiquitäre $\beta$-Aktin-mRNA in vivo

analysiert werden. Die Expression von MS2 CP-GFP hatte keinen Einfluss auf die Lebensfähigkeit der Tiere. In Saccharomyces cerevisiae musste hingegen die starke Bindung des MS2-CPs abgeschwächt werden, da ansonsten mRNA-Abbauprodukte angereichert wurden. Um die dynamische Lokalisation der mRNAs zu untersuchen, reicht ein sensitives Fluoreszenzmikroskop aus. Bewegung wird durch die schnelle Abfolge von Aufnahmen dokumentiert. Einzelbilder könnten zu einem Film zusammengefasst und mithilfe eines Kymographen analysiert werden. Die Bewegung von mRNAs wird als diagonale Linien sichtbar (Abb. 2). Mithilfe eines Mikroskopmoduls, das die gleichzeitige Aufnahme mehrerer Wellenlängen erlaubt, können Ko-Lokalisationsstudien mit mehreren mRNAs und/ oder Proteinen durchgeführt werden.

\section{Aktin-abhängiger mRNA-Transport in Saccharomyces cerevisiae}

Das Labor von Rob Singer am Einstein College of Medicine, New York, etablierte das MS2-System in S. cerevisiae zur Untersuchung des ASH1-mRNA-Transports [2]. In S. cerevisiae wechselt die Mutterzelle nach jeder Teilung den Paarungstyp. Dieser Wechsel basiert auf einer Endonuklease, die spezifisch am Paarungstyp-Locus einen Doppelstrangbruch einführt und so einen Wechsel initiiert. Der Transkriptionsfaktor Ash1p reprimiert die Expression des EndonukleaseGens spezifisch in der Tochterzelle und verhindert so den Wechsel des Paarungstyps. Hierbei spielt der aktive Transport der ASH1mRNA eine entscheidende Rolle, da sich diese während der Teilung in der Tochterzelle

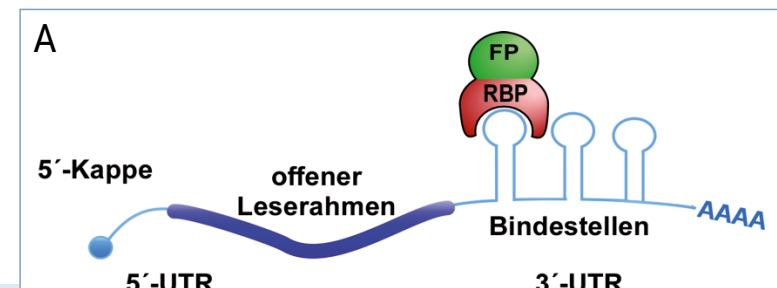

Abb. 1: Grundprinzip des RNA-Live-Imagings. A, Schematische Darstellung des RNA-Live-Imagings. In die 3'-untranslatierte Region (UTR) einer mRNA (blau) werden RNA-Haarnadelschleifen integriert, die ein passendes RNA-bindendes Protein (RBP, rot) spezifisch erkennt. Das RBP wird fusioniert mit einem Fluoreszenzprotein (FP, grün) exprimiert (nach [12]). B, Vergleich von drei gängigen Systemen: Im $\lambda N$ System bindet RBP $\left(\lambda N^{*}\right.$, braun) als Monomer; im PP7- und MS2-System bindet RBP (PCP, pink; MCP, gelb) als Dimer.

3'-UTR

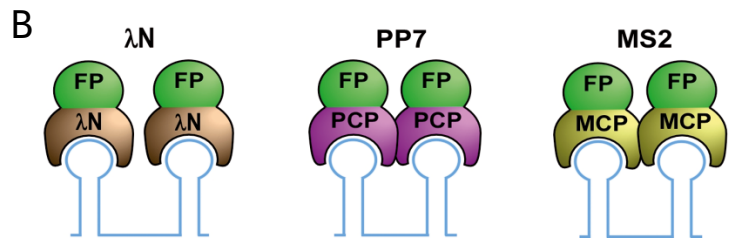




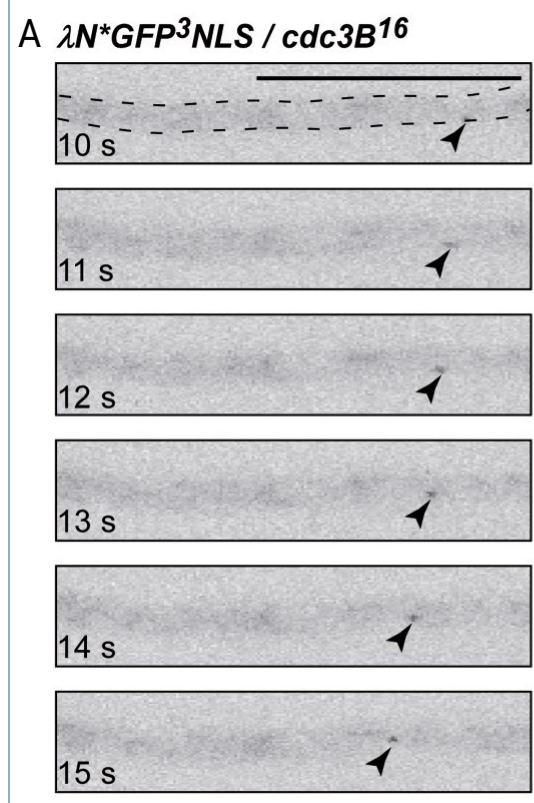

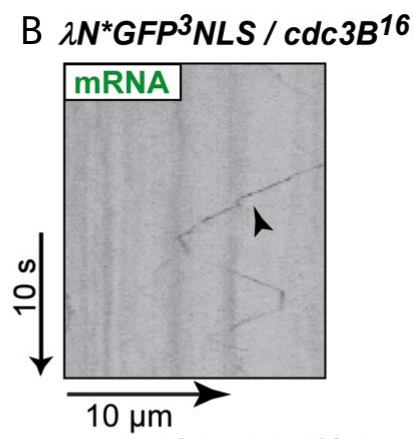
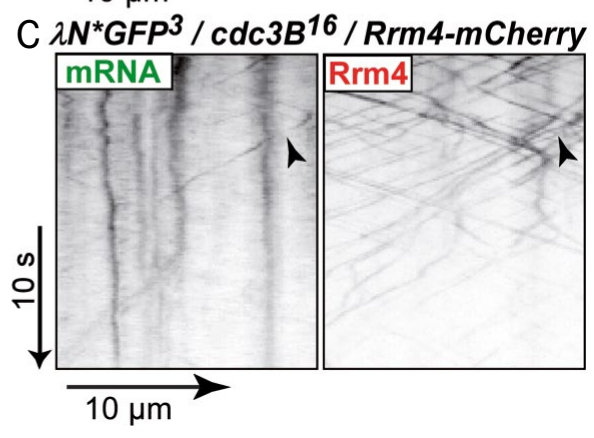

Abb. 2: RNA-Live-Imaging am Beispiel von Ustilago maydis. A, Fluoreszenzmikroskopische Aufnahmen eines Ausschnitts einer Hyphe (gestrichelte Linie). Für eine bessere Darstellung wurde der Kontrast invertiert. Die sechs Bilder wurden im Abstand von einer Sekunde aufgenommen (Belichtungszeit: 150 Millisekunden). Die schwarzen Pfeilspitzen deuten auf $c d c 3-m R N A-S i g n a l e$, die als schwarze Punkte erkennbar sind. Sie bewegen sich zeitabhängig in einer Hyphe von rechts nach links (Größenstandard: $10 \mu \mathrm{m}$ ). B, Fluoreszensmikroskopische Aufnahmen (A) werden in einem Kymographen zusammengefasst. Die prozessive Bewegung eines mRNA-Partikels (von rechts nach links; Pfeilspitze) wird als diagonale Linie erkennbar (Zeit und Distanz sind angeben). Die dynamische Bewegung der cdc3B16-mRNA (16 BoxB-Bindestellen) wird sichtbar, weil das RNA-bindende Protein (RBP) $\lambda N^{*}$, fusioniert mit Dreifach-GFP, an seine BoxB-Bindestellen im 3'-UTR bindet. C, Hier wird die Ko-Lokalisation einer cdc3-mRNA (grün, links) und des RBPs Rrm4mCherry (rot, rechts) analysiert. Aufnahmen wurden mit einem speziellen Mikroskopmodul aufgenommen (siehe Text). Die Pfeilspitzen zeigen in den jeweiligen Kymographen Ko-Lokalisationsereignisse an.

sammelt. Fluoreszenz-in situ-Hybridisierung bestätigte diese Lokalisation. Allerdings fehlt bei dieser Analyse die Information, wie und wann die mRNA in die Tochterzelle gelangt. Mithilfe von RNA-Live-Imaging konnten Mitarbeiter von Singer erstmals den aktiven Transport der mRNA entlang des Aktincytoskeletts in die Tochterzelle verfolgen. $\mathrm{Zu}$ diesem Zweck fusionierten sie das grün fluoreszierende Protein (GFP) an das MS2-CP und integrierten MS2-Bindemotive in die 3'-UTR der ASH1-mRNA. In weiteren Studien wurde mithilfe des MS2-Systems der KoTransport von mRNAs mit dem tubulären endoplasmatischen Retikulum (tER) beobachtet, das während der Teilung ebenfalls in die Tochterzelle migriert [3]. Folglich könnte die Migration des tERs für die korrekte tochterzellspezifische Lokalisation von mRNAs, die für Membran- oder ER-assoziierte Proteine codieren, wichtig sein.

\section{RNA-Live-Imaging deckt endosomalen mRNA-Transport in $U$. maydis auf}

Der Langstreckentransport von mRNAs entlang des Mikrotubulicytoskeletts ist in polar wachsenden Zellen wie Neuronen oder Pilzhyphen besonders wichtig. Der Mikrotubuliabhängige Transport wurde in Mikroorganismen erstmals in Infektionshyphen des Maispathogens Ustilago maydis nachgewiesen. Der Transport basiert auf Endosomen und dem Schlüssel-RBP Rrm4. Rrm4 transportiert eine Vielzahl von mRNAs bidirektional durch die Zelle. Kommt es zum Verlust von Rrm4, fehlt den Hyphen ein Anhaltspunkt, um eine korrekte Polaritätsachse auszubilden. Folglich wachsen die Hypen bipolar [4]. Ebenfalls kommt es zu einer Fehllokalisation von Proteinen, deren mRNAs von Rrm4 transportiert werden. Dies wurde für Septinproteine gezeigt, die heteromere Komplexe bilden und unter anderem an Zellpolarität und Zellmorphologie beteiligt sind. Eine Fusion von GFP an $\lambda \mathrm{N}^{*}$ und die Integration von RNA-Bindemotiven in die 3'-UTR von Septin-mRNAs ermöglichten erstmals die Aufdeckung des Transports von mRNAs zusammen mit Endosomen entlang von Mikrotubuli (Abb. 2). Mithilfe von RNA-Live-Imaging war es möglich, eine Ko-Lokalisation der cdc3-mRNA, des codierten Septinproteins und der Endo- somen $\mathrm{zu}$ visualisieren [5]. Zusammen mit der mRNA-abhängigen Ko-Lokalisation von Rrm4 und Ribosomen beobachteten wir mithilfe von RNA-Live-Imaging erstmalig den membrangekoppelten Transport von translational aktiven mRNPs [6]. Ein vergleichbarer Transportmechanismus wurde vor Kurzem in Neuronen gezeigt, was für eine evolutionäre Konservierung dieses membrangekoppelten Prozesses spricht [7].

\section{RNA-Live-Imaging in Bakterien}

Auch in Bakterien spielt die zeitliche und räumliche Kontrolle der Expression von Proteinen eine große Rolle. Mittels RNA-LiveImaging wurden in Bakterien verschiedene mRNA-Lokalisationsmuster identifiziert [8]. Im Gram-positiven Bakterium Bacillus subtilis gelang es durch eine Fusion des MS2-CP an GFP und die Integration von MS2-Bindemotiven, die Lokalisation der comE-mRNA an den Zellpolen und Septen nachzuweisen. Mithilfe des MS2-Systems wurde in Escherichia coli die Lokalisation des lacY-Transkripts an der Membran gezeigt. Die mRNA codiert für die membrangebundene Laktosepermease.

Durch die geringere Größe von Bakterien reicht die Fluoreszenzmikroskopie nicht immer aus, um eine detaillierte Information über die Lokalisation zu erhalten. Aus diesem Grund werden mRNAs häufig mit superresolution-Mikroskopie betrachtet. Eine massive Erhöhung der Anzahl der RNA-Bindemotive innerhalb der 3'-UTR der mRNA und damit die Anzahl an gebundenen RBPs beeinflusst die Diffusionsgeschwindigkeit des Transkripts. In eukaryotischen Mikroorganismen wandern ungebundene RBP-Fluoreszenzproteine (FPs), die mit einem Kernlokalisationssignal fusioniert sind, in den Zellkern. In den Zellkern-freien Prokaryoten ist dies nicht möglich. Das erschwert die Visualisierung der mRNAs. Um die Hintergrundfluoreszenz zu minimieren, können neben photoaktivierbaren auch photokonvertierbare Fluoreszenzproteine eingesetzt werden.

\section{RNA-Live-Imaging als Basis für die Analyse zellulärer Prozesse}

Das RNA-Live-Imaging bietet ein leistungsstarkes Werkzeug für die Analyse der Lokalisation von mRNAs in vivo. Die Methodik wird für neue Fragestellungen stetig weiterentwickelt. Die Markierung einer mRNA mit mehreren Systemen erlaubt nun, sowohl die Translation als auch den Abbau in vivo zu visualisieren $[9,10]$. Hierfür wird die mRNA 
mit zwei unterschiedlichen RBP-FPs markiert, sodass zwei Fluoreszenzproteine eine mRNA binden. Wird eines durch das Ribosom oder durch eine Ribonuklease entfernt, zeigt der Wechsel der Fluoreszenz die Translation oder den Abbau der mRNA an. Die Translation kann auch mithilfe der Markierung der 3'-UTR einer mRNA und der gleichzeitigen Markierung der wachsenden Polypeptidkette mithilfe eines Antikörpers in vivo beobachtet werden [11]. Basierend auf diesen vielversprechenden Weiterentwicklungen sollte zukünftig eine detaillierte, quantitative Analyse der zugrunde liegenden zellulären Mechanismen möglich sein. Diese Informationen werden präzise klären, wann und wie lange mRNAs in definierten subzellulären Bereichen in vivo translatiert werden. Damit lassen sich wichtige Vorhersagen über die darauffolgenden Prozesse treffen, wie z. B. die Komplexbildung der Translationsprodukte. Folglich ist das RNA-Live-Imaging eine hervorragende Methode, um verschiedene Prozesse der RNA-Biologie in lebenden Organismen zu untersuchen.

\section{Danksagung}

Wir bedanken uns bei den Mitarbeiterinnen und Mitarbeitern des Instituts für die Diskussionen und das kritische Lesen des Manuskripts. Unsere Forschung wird unterstützt durch Fördermittel der Deutschen Forschungsgesellschaft (DFG).

\section{Literatur}

[1] Tutucci E, Livingston NM, Singer RH et al. (2018) Imaging mRNA in vivo, from birth to death. Annu Rev Biophys 47:85-106

[2] Bertrand E, Chartrand P, Schaefer M et al. (1998) Localization of ASH1 mRNA particles in living yeast. Mol Cell 2:437-445
[3] Fundakowski J, Hermesh O, Jansen RP (2012) Localization of a subset of yeast mRNAs depends on inheritance of endoplasmic reticulum. Traffic 13:1642-1652 [4] Becht P, König J, Feldbrügge M (2006) The RNAbinding protein $\mathrm{Rrm} 4$ is essential for polarity in Ustilago maydis and shuttles along microtubules. J Cell Sci 119:4964-4973

[5] Zander S, Baumann S, Weidtkamp-Peters S et al. (2016) Endosomal assembly and transport of heteromeric septin complexes promote septin cytoskeleton formation. J Cell Sci 129:2778-2792

[6] Baumann S, König J, Koepke J et al. (2014) Endosomal transport of septin mRNA and protein indicates local translation on endosomes and is required for correct septin filamentation. EMBO Rep 15:94-102

[7] Cioni JM, Lin JQ, Holtermann AV et al. (2019) Late endosomes act as mRNA translation platforms and sustain mitochondria in axons. Cell 176:56-72

[8] Fei J, Sharma CM (2018) RNA localization in bacteria. Microbiol Spectr 6, doi: 10.1128/microbiolspec.RWR-0024 2018

[9] Halstead JM, Wilbertz JH, Wippich F et al. (2016) TRICK: a single-molecule method for imaging the first round of translation in living cells and animals. Methods Enzymol 572:123-157

[10] Horvathova I, Voigt F, Kotrys AV et al. (2017) The dynamics of mRNA turnover revealed by single-molecule imaging in single cells. Mol Cell 68:615-625

[11] Wang C, Han B, Zhou R et al. (2016) Real-time imaging of translation on single mRNA transcripts in live cells Cell 165:990-1001

[12] Zander S, Müntjes K, Feldbrügge M (2018) RNA live maging in the model microorganism Ustilago maydis. Methods Mol Biol 1649:319-335

Funding: Open Access funding provided by Projekt DEAL. Open Access: Dieser Artikel wird unter der Creative Commons Namensnennung 4.0 International Lizenz veröffentlicht, welche die Nutzung, Vervielfältigung, Bearbeitung, Verbreitung und Wiedergabe in jeglichem Medium und Format erlaubt, sofern Sie den/die ursprünglichen Autor(en) und die Quelle ordnungsgemäß nennen, einen Link zur Creative Commons Lizenz beifugen und angeben, $O b$ Anderungen vorgenommen wurden. Die in diesem Artikel enthaltenen Bilder und sonstiges Dritmaterial unterliegen ebenfals er genanten Crealive Commons Lizenz, sofern sich aus der Abildungslegende nichts anderes ergibt. Sofern das betreffende Materia betreffende Handlung nicht nach gesetzlichen Vorschriften erlaubt ist, ist für die oben aufgeführten Weiterverwendungen des Materials die Einwilligung des jeweiligen Rechteinhabers einzuholen. Weitere Details zur Lizenz entnehmen Sie bitte der Lizenzinformation auf http://creativecommons.org/ licenses/by/4.0/deed.de.

Korrespondenzadresse:

Prof. Dr. Michael Feldbrügge

Institut für Mikrobiologie, Cluster of Excellence on Plant Sciences

Heinrich-Heine-Universität Düsseldorf

Universitätsstraße 1

D-40225 Düsseldorf

feldbrue@hhu.de

www.mikrobiologie.hhu.de

Kira Müntjes
$2010-2015$ Biologiestudium an der Universität Düsseldorf; dort seit 2015 Promo-
tionsstudentin in der Gruppe von Prof. Dr. M. Feldbrügge.
Michael Feldbrügge
1992-1995 Promotion am Max-Planck-Institut für Züchtungsforschung in Köln.
1995-1998 wissenschaftlicher Mitarbeiter am Plant Research Laboratory, Michi-
gan State University, East Lansing, USA, als DFG-Stipendiat. 1998-2000 wissen-
schaftlicher Mitarbeiter in der Arbeitsgruppe von Prof. Dr. R. Kahmann am Institut
für Genetik und Mikrobiologie, LMU München. 2000-2009 Arbeitsgruppenleiter
und Privatdozent in der Abteilung für terrestrische Mikrobiologie, Max-Planck-Insti-
tut Marburg. 2007 Habilitation im Fach Genetik an der Universität Marburg. Seit
2009 Professur für Mikrobiologie an der Universität Düsseldorf.

